\title{
MICROSTRUCTURE ANALYSIS OF STEEL 85 \& AL-7050 FOR COLD EXPANDED HOLES
}

\author{
Basavaraj ${ }^{1}$, Shanmukh. $\mathbf{N}^{2}$ \\ ${ }^{1}$ Associate Prof. MED, BKIT, Bhalki \\ ${ }^{2}$ Professor RVCE, Bangalore
}

\begin{abstract}
Introduction of beneficial compressive residual stresses at fastener hole to retard the cracking in material subjected to fatigue loading.

Among various techniques, cold expansion is most oftenly used to achieve the introduction of compressive stresses. The present work investigates the microstructure changes along the radial selling section of holes after the cold working of holes. Two different materials, steel 85 \& AL-7050 with thickness $12 \mathrm{~mm}$ and $6 \mathrm{~mm}$ were selected for conducting experiment. The split sleeve method was used to expand the holes to different percentage and microstructures are observed using SEM. Micro graphs clearly showed a zone of plastic deformation close to the hole fallowed by a zone of elastic compression induced by the split sleeve expansion. The pattern after different extent of expansion of holes was studied and comparative study of microstructure of holes, before and after expansion was done.
\end{abstract}

Keywords: Residual stresses, cold hole expansion microstructure, split sleeve process, micro graph.

\section{INTRODUCTION}

Fatigue has become a very important phenomenon, as the need for higher strength to weight ratio of engineering component is more; especially in aircraft, compressors, automobile, turbines etc. which are subjected to repeated loading \& vibration.

Aircraft industry shows the considerable interest in the influence of beneficial residual compressive stresses on fatigue behavior of component [1]. These compressive residual stresses are highly effective in preventing premature fatigue failure under condition of cyclic loading $[2,3]$. The common structural features that assimilates stresses are fastener holes in structural joints, lug attachments and open holes are a major source of fatigue cracking. One of the most prevalent sources of aircraft structural failure are cracks emanating from fastener holes. Some methods have to be developed to increase the service life of components and one of these methods used in this is to form a controlled compressive residual stress field around the fastener hole [4, 5]. Use of thicker structure a change in material specification or a redesign is the possibilities to reduce the effect of fatigue, but all these invariably increase either the cost wait. To build in fatigue resistance in to the critical assemblies providing greater safety and fatigue life would be an ideal solution.

To increase fatigue life of both new and renovated aircraft structures, cold expansion of fastener holes is used [6]. Expansion of hole is accomplished by the split-sleeve process by putting tapered mandrel pre fitted with a lubricated split sleeve through the hole. To generate prescribed amount of plastic deformation around the hole, the mandrel and sleeve are designed, which in turn creates a state of biaxial residual compressive stress in that area.

The method is an oversized mandrel is drawn through a fastener hole in order to course plastic deformation and leave a beneficial compressive residual stress at the hole edge [7]. On removal of the mandrel owing to the spring back of the surrounding elastic material, residual stress field is produced with compressive residual stresses in an annular region adjacent to the hole.

Split-sleeve cold expansion is used primarily by the civil aircraft industry, and extra care has to be taken to ensure that the correct degree of expansion is achieved, as the holes are usually damaged from service as a result of wear corrosion, scoring, cracking etc. $[1,5]$.

The common practice to remove damage is by reaming or drilling \& reaming before cold expansion, but it is possible that cracks are still present even after such operation [8].

Most of the civil craft components are designed using the damage tolerant approach. By this, the emphasis is on the control of the crack growths rates and on effective periodic inspection, with the requirement for the crack detection techniques to be able to identify flows of a certain size [9]. Little impact was noticed on fatigue crack initiation, fatigue 
crack growth may be significantly delayed or even arrested by compressive cold expansion residual stresses [6, 10]. Static compressive loading, resulting in the charge of cold expansion residual stresses was studied by steanfanescu et al [11] by experimental approach i.e; direct stress measurement using diffraction techniques and it was found that the above approach affected both the magnitude and the shape of residual stress distribution.

No reliable method is currently available to calculate the relevant effective stress intensity factor accurately for use in predictions of fatigue crack growth for cracks emanating from cold expanded fastener holes. As a result, although cold expansion is frequently used in practice, no account is taken of the endurance gain in the fatigue life assessment procedure at the design stage

\section{EXPERIMENTAL PROCEDURE}

\subsection{Specimen Preparation}

Rectangular plate specimens of dimensions $320 \mathrm{~mm} \times 42 \mathrm{~mm} \times$ $12 \mathrm{~mm}$, were used for this work. The specimens were cut from a plate made from aluminium, and steel (alloy steel) for study of microstructure. Specimens were drilled to $12.5 \mathrm{~mm}$ and reamed to $13 \mathrm{~mm}$. Before cold expansion a mechanical procedure was used for preparation of the specimen surfaces. Preparation was necessary in order to remove all superficial defects that could have served as initiation sites for fatigue cracks, leading to premature failure of the specimens. Also, polishing the specimen surface allowed accurate optical monitoring of the crack growth. Firstly, each specimen, held in a specially designed device, was mechanically ground using 300 and 500 grit emery paper. The mechanical grinding operation was carried out on a Buehler Variable-speed grinder-polisher machine using the following parameters: wheel speed $240 \mathrm{rpm}$, load $22.6 \mathrm{~N}$ and time $5 \mathrm{~min}$. The grinding was then continued manually along the rolling direction, using 1100 grit emery paper, till marks were present only along that direction. The surface preparation was finished with polishing using MD Nap cloth and Buehler $3 \mu \mathrm{m}$ diamond compound. The polishing operation was carried out on the same machine using the following parameters: wheel speed $380 \mathrm{rpm}$, load $36.6 \mathrm{~N}$ and time $3 \mathrm{~min}$. A specially designed wheel was used to ensure polishing only in the central area of the specimens. The specimen round edges were also manually ground and polished to reduce the stress concentration in that area.

\subsection{Cold Hole Expansion}

All specimens were double cold expanded in opposite directions using cold hole expansion test rig. The area at the edge of the hole subjected to a non-uniform radial expansion due to $t$ he split of the sleeve, usually termed the 'pip', was placed along the longitudinal direction of each specimen.
Previous studies on double cold expansion showed that it reduces the through thickness variation of the residual stress field and promotes cracks with a simple geometry. The residual stresses generated by the first cold expansion on the initial mandrel entrance face (inlet) are significantly affected (increased) by the repeated cold expansion, whereas the residual stresses on the initial mandrel exit face (outlet) are almost unchanged. Fracture surface examination of fatigue loaded double cold expanded specimens showed a straight front for short through-thickness cracks and a curved front for longer through-thickness cracks. In contrast, cracks growing from single cold expanded holes usually have a highly irregular, bulbous front, even for small lengths. It can be observed that double cold expansion is a suitable specimen preparation technique for this work where little throughthickness variation in residual stress and simple crack geometries are required.

After double cold expansion was applied, a $0.2 \mathrm{~mm}$ throughthickness starter slot was introduced into each specimen at the edge of the hole, along the transverse direction passing through the center of the hole by electric discharge machining (EDM), using a $0.16 \mathrm{~mm}$ copper wire. The slot ensured that a through-thickness crack initiated at the bore of the hole at the correct location from the early stages of the subsequent cycling

\subsection{Specimen Preparation for Micro-Structure Studies}

The following steps are adopted for the specimen preparation:

\subsubsection{Fine Grinding}

The specimen surface is ground using SIC powder bonded onto specially prepared papers. The specimen is hand rubbed against abrasive paper which is laid over flat surface. 7 grades of abrasive papers were used. In proceeding from one paper to the next, the specimen is rotated through an angle of 450 so that the new scratches are placed on the surface at angle to those formed during the preceding stage.

\subsubsection{Polishing}

The abrasive used for the polishing operation is powdered diamond dust. The diamond powder is mixed in an oil so as to form a paste. This paste is placed on a nylon cloth-covered surface of a rotating polishing wheel. The specimen is moved around the wheel in a direction to the rotation of the wheel to ensure uniform polishing action, which results in a scratch free surface.

\subsubsection{Etching}

Grain boundaries in a metal have a thickness of the order of a few atom diameters and the resolving power of the microscope is low to reveal their presence, so the specimens are etched. 
This involves immersing the specimens in a weak acidic or alkaline etching solution example Nital.

\section{STUDY OF MICROSTRUCTURE USING SCANNING ELECTRON MICROSCOPE (SEM)}

The holes on the metal plates of Stee185, AL-7050were expanded successfully to different extent using the Cold Hole Expansion Rig. Up to $4 \%$ expansion was achieved on aluminium and steel effectively expanded up to $2 \%$. The micrographs show clearly the pattern of plastic and elastic deformation zones created due to the expansion of holes. The zones indicate the region of compressive stress. The grain boundaries can be seen to be compressed. The arrows in the figures below Indicates the direction of the force acting on the holes. It can be seen that the compressive zones formed are perpendicular to the radial force acting on the hole

\subsection{Microstructures of Aluminium7050}

Micrographs of Aluminium 7050 plates of $6 \mathrm{~mm}$ thickness expanded up to $4 \%$ in the interval of $2 \%$ are shown in figures 3.11 to 3.13. Fig:3.11 show the microstructure of A17050 alloy without any hole expansion with smaller magnification.. The grain boundaries are very clear \& distinguishable with one other when there is no hole expansion. Fig:3.12 show the micrographs of Al7050 with 2\% hole expansion. The direction of arrows indicates the direction of application of the compressive forces to bring about the hole expansion. The grains in this micrograph is not clearly visible. From Fig:3.12, it is observed that the lighter layers are zones of plastic deformation and darker layers are the zones of elastic deformation. The layers denser in the neighborhood of the fastener hole and spread apart \& move away from the loading region.

Fig: 3.13 shows the micrograph with $4 \%$ hole expansion with lower magnification. It is observed from the graph that the layers of plastic deformation dominate the layers of elastic deformation. This justifies the fact that plastic deformation increases with the increase in percentage of expansion of the hole. The weakest compressive peak stresses are near the inlet (mandrel entrance) surface. The plastic deformation regions are concentrated densely near the holed section. The plastic deformation regions seen near the holed section are thicker in size than those sections away from the holed section. It is observed from the micrographs that a zone of plastic deformation close to the hole followed by a zone of elastic compression induced by the split sleeve expansion.

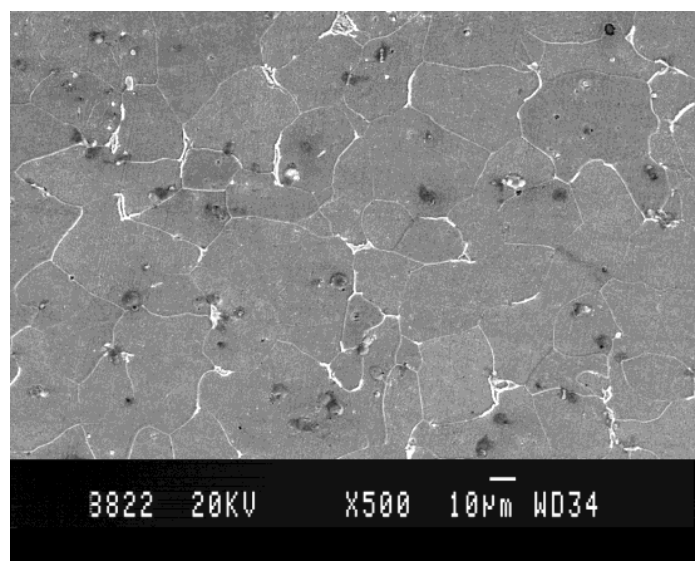

Fig 3.11: Aluminium 7050 without pre-stressing lower magnification

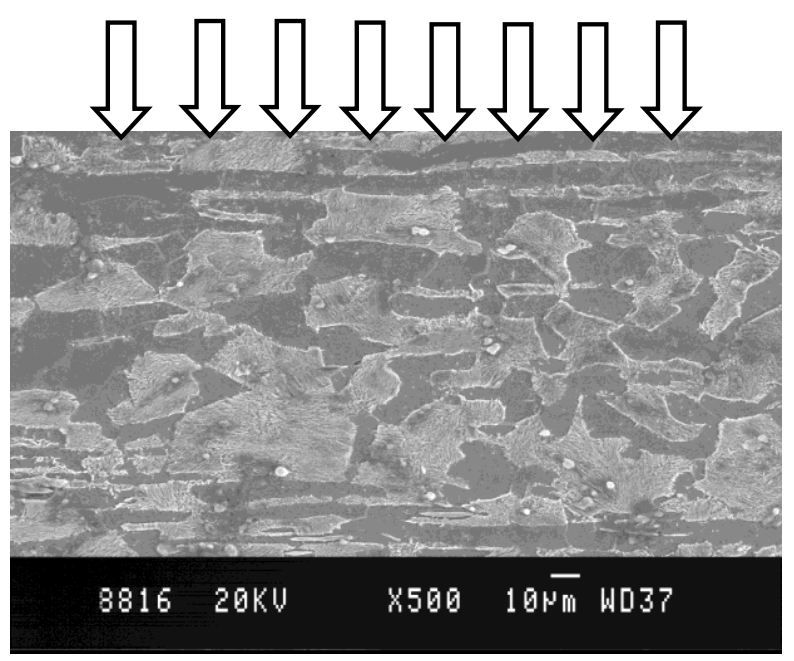

Fig 3.12: Aluminium 2\% expansion lower magnification

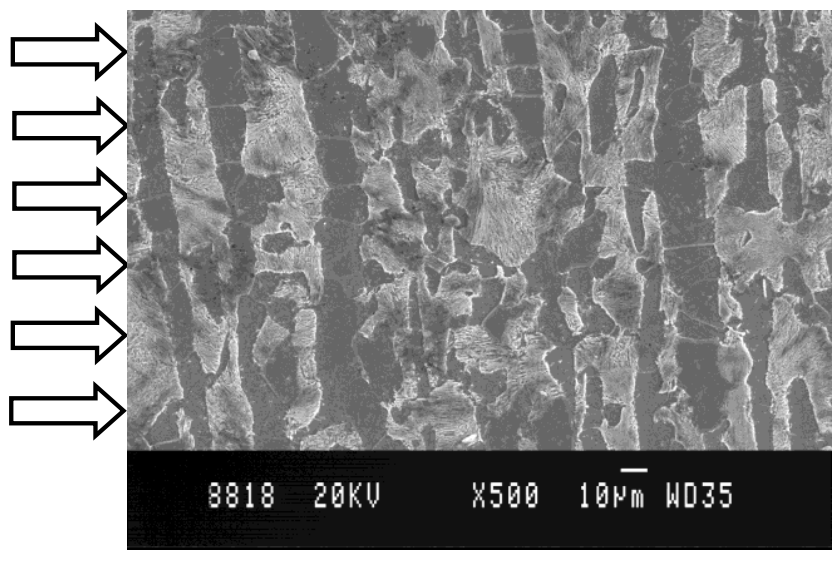

Fig 3.13: Aluminium 4\% expansion lower magnification 


\section{MICROSTRUCTURES OF STEEL}

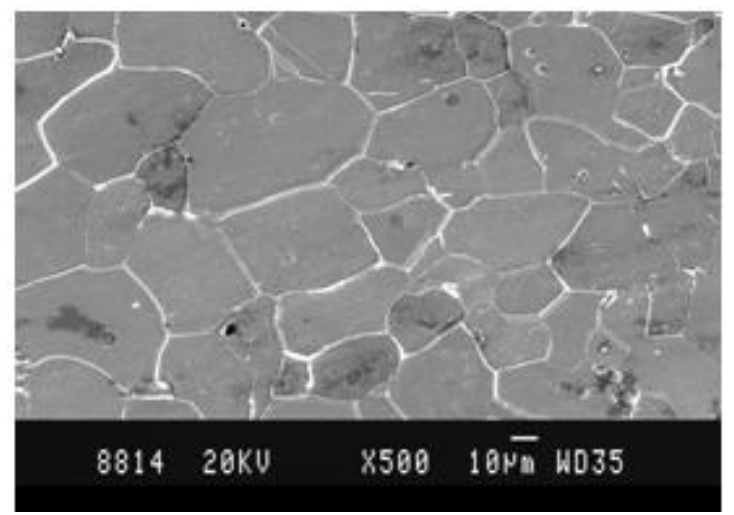

Fig 4.11: Microstructure of steel with $0 \%$ expansion

Fig: 4.11 show the microstructure of a section of hole cut from steel. The grains are distinguishable from one another. Carbon can be seen as black spots and lighter spots are other alloying elements.

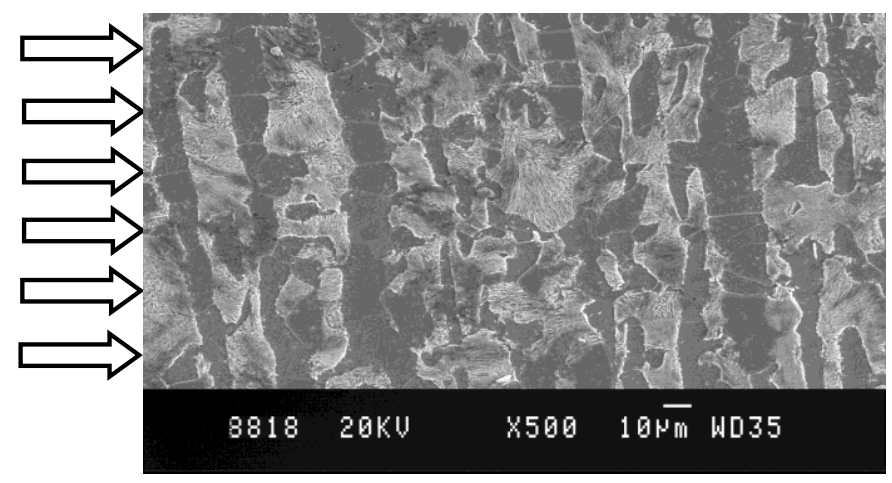

Fig 4.12: Microstructure of steel with $1.2 \%$ hole expansion

The grains in 1.2\% cold-expanded hole (Fig. 4.12) are closer together when compared to grains in non-expanded holes. The thickness of the grain boundaries has reduced considerably. The carbon particles appear to be frayed. The expansion of $1.2 \%$ has not brought about any significant plastic deformation in the cross section of the hole. But, the compression can definitely be noticed from the photograph.

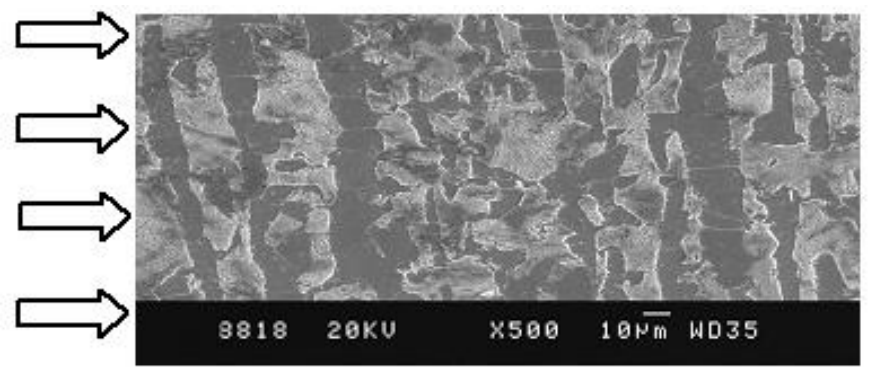

Fig 4.13: Microstructure of steel with $2 \%$ hole expansion
2\% cold-expanded hole (Fig:4.13) shows distinct layers of plastic and elastic deformation. The layers are closely packed near the point of application of load and are farther away from one another as the distance from the load increases. The grain boundaries cannot be distinguished very easily. Carbon particles have broken into finer particles and are dispersed mainly in the elastic deformation zone.

Some fracto graphic evidence suggests that the residual stress distributions may not be uniform across the thickness of the work piece and it has been suggested that the residual stresses near the mandrel exit (outlet) face of the hole are greater than the stresses near the mandrel entrance (inlet) face. Thus, there is evidence that split-sleeve expansion is a complicated threedimensional process and two-dimensional representations of the resultant residual stresses may not be appropriate.

\section{CONCLUSIONS}

Two different materials, namely steel85 and AL7050 with thickness $12 \mathrm{~mm} \& 6 \mathrm{~mm}$ used to conduct the experiment. Methodology based fatigue crack growth prediction taking into account residual stress change for different expansion was verified. The revelation of micrographs is summarised as.

$>$ The fatigue life increases due to cold deformation, which results in introduction of compressive residual stress field around the hole.

$>$ With increasing crack layers, the maximum compressive residual stress decreases on both focuses, the decreasing rate is similar on each face.

$>$ Clear visibility of layers of plastic \& elastic regions.

$>$ The deformation plastic \& elastic is irregular in nature.

$>$ Chances of high tensile residual stresses due to improvement cold expansion of adjacent hole

$>$ Increase in percentage of expansion loads to increase in number of layers.

$>$ The inlet (mandrel entrance) surfaces are the location for weakest compressive peak stresses.

$>$ The plastic deformation regions seen near the holed section are thicker in since than those away from hole section.

\section{REFERENCES}

[1] Leitao, V.MA., Aliabadi, M.H., Rooke, D.P. and Cook, R. Boundary elemen

[2] $t$ methods for the analysis of crack growth in the presence of residual stress fields.

[3] Champoux, R.L., Overview of hole cold expansion methods. Proceddings of the international Conference on Fatigue Prevention and Design, Amesterdam, The Netherlands, 1986, pp. 35-61.

[4] Landy, M.A., Armen Jr., H., and Eidnoff, h. L., Enhanced stop-drill repair procedure for cracked structures. Fatigue in Mechanically Fastened 
Composite and Metal Joints. ASTM STP , 1986, 927, 190.

[5] N. Chandawanich and W.N. Sharpe Jr., Eng. Fract. Mech., (1979) 11.

[6] X. Su, M. Go and M. Yan. Fatigue Fract. Eng. Mater. Struct., (1986)9.

[7] Ball, D.L. and Lowry, D.R. Experimental investigation on the effects of cold expansion of fattener holes. Fatigue and Fracture of Engng Mater. Structs, 1998, 21(1), 17-34.

[8] FTI 81011C Cold Expansion of Holes Using the Standard Split Sleeve System (Cx) and Countersink Cold Expansion, 1994 (Engineering Process Specification, fatigue Technology Inc., Seattle, Washigton).

[9] Holdway, P., and Cook, R. (1997). "Effect of cold expansion on the residual stress distribution and fatigue prolperties in a alloy 7050 containing fastener holes w3ith residual fatigue cracks" Proc., $5^{\text {th }}$ Int. Conf. On Residual stresses. T. Ericsson, M. Oden and A. Andersson eds., Univ. of Linkoping, Linkoping, Sweden, 76-81.

[10] Suresh, S. Fatigue of Materials, $1^{\text {st }}$ edition, 1991, Cambridge Solid State Science Series (Cambridge University Press, Cambridge).

[11] Fitzpatrick, M.E. and Edwards, L. Fatigue crack/residual stress field interaction and their implications for damage-tolerance design. J. Mater. Engng and Performace, 1998, 7(2) 190-198. 